\title{
A dominantly inherited lower motor neuron disorder presenting at birth with associated arthrogryposis
}

\author{
P FLEURY,* G HAGEMAN $\dagger$ \\ From the Department of Childneurology, Academical Medical Centre, University of Amsterdam, ${ }^{*}$ and the \\ Department of Childneurology, University Hospital Utrecht, $\dagger$ The Netherlands.
}

SUMMARY Of a family consisting of 54 members, 44 were examined. Twenty-one showed signs of a clinically non-progressive congenital lower motor neuron disorder restricted to the lower part of the body, which resulted in arthrogryposis in 15 cases. The mode of inheritance is autosomal dominant with very varied expression of the gene.

In infants presenting at birth with weakness and associated arthrogryposis, the diagnosis of a neuromuscular disorder is probable. Beside the clinical signs, the use of electromyography, nerve condition velocity studies, muscular and sometimes cerebral CT scanning and muscle and/or nerve biopsies will be necessary for the differential diagnosis. ${ }^{1}$ When disorders of the upper motor neuron, motorend-plate disturbances or primary degeneration of muscle are excluded, the diagnosis of a congenital neurogenic syndrome remains.

Disorders of the lower motor neuron with antenatal onset and congenital contractures are rare. The most frequent of these disorders is anterior horn cell degeneration, of which the time of onset is more likely during the third month of pregnancy, that is in the critical period of differentiation of the spinal motor neuron. ${ }^{2}$ Severe congenital contractures are characteristic findings in anterior horn cell degeneration, an infantile neurogenic muscular atrophy distinct from Werdnig-Hoffman disease because of an apparent arrest of the disease process. $^{3}$

In one-third of the cases, spinal muscular atrophy type I may have a prenatal time of onset, probably from the 26th week of gestation, leading to decreased fetal movements and in some cases to congenital contractures. Primary lesions of the anterior roots leading to arthrogryposis multiplex congenita were demonstrated by Bargeton et $a^{4}$ in two male stillbirths of consanguinous parents.

\footnotetext{
Address for reprint requests: P Fleury, MD, Department of Childneurology, Academical Medical Centre, Meibergdreef 9, $1105 \mathrm{AZ}$ Amsterdam, The Netherlands.
}

Received 8 August 1984 and in revised form 8 February 1985. Accepted 16 February 1985
The range of onset for patients with hereditary motor and sensory neuropathy type $I$ is very similar to that of spinal muscular atrophy type I. Cases of hereditary motor and sensory neuropathy type II almost always present in the second decade, but in a considerable number there is a much later onset. However, cases with very early onset, sometimes possibly antenatal, with associated deformities like pes cavus and scoliosis have been reported. ${ }^{5}$

The present paper deals with a Dutch family consisting of 54 members, running through four generations. We investigated 44 members of this family (fig 1). Of them 21 (now aged 8-66 years) show signs of a clinically non-progressive neurogenic syndrome with antenatal onset associated in 15 members of the family with arthrogryposis. Remarkably, in this family, the muscle weakness, atrophy and congenital contractures are restricted to the lower part of the body. The mode of inheritance was dominant, probably autosomal.

\section{Case histories}

Case 1: The index case (fig 1: III; 20 and fig 9) was born after an uneventful pregnancy and labour. At birth she showed bilateral talipes equinovarus in adduction and internal rotation, flexion contractures of the knees and flexion contractures of the hips. She underwent orthopaedic corrections of the knees and the feet at the age of two years. After that she could walk with crutches, showing a marked lordosis and forward tilting of the pelvis, due to the flexion contractures at the hips. At the thoracic level she showed a slight scoliosis with convexity to the right. In the hips restriction of movements was from $50^{\circ}$ flexion to $100^{\circ}$ extension, in the knees from $50^{\circ}$ flexion to $140^{\circ}$ extension and practically complete in the feet. Abduction and adduction, and rotation of the hips were also limited. The knees had a fusiform appearance. Neurologi- 


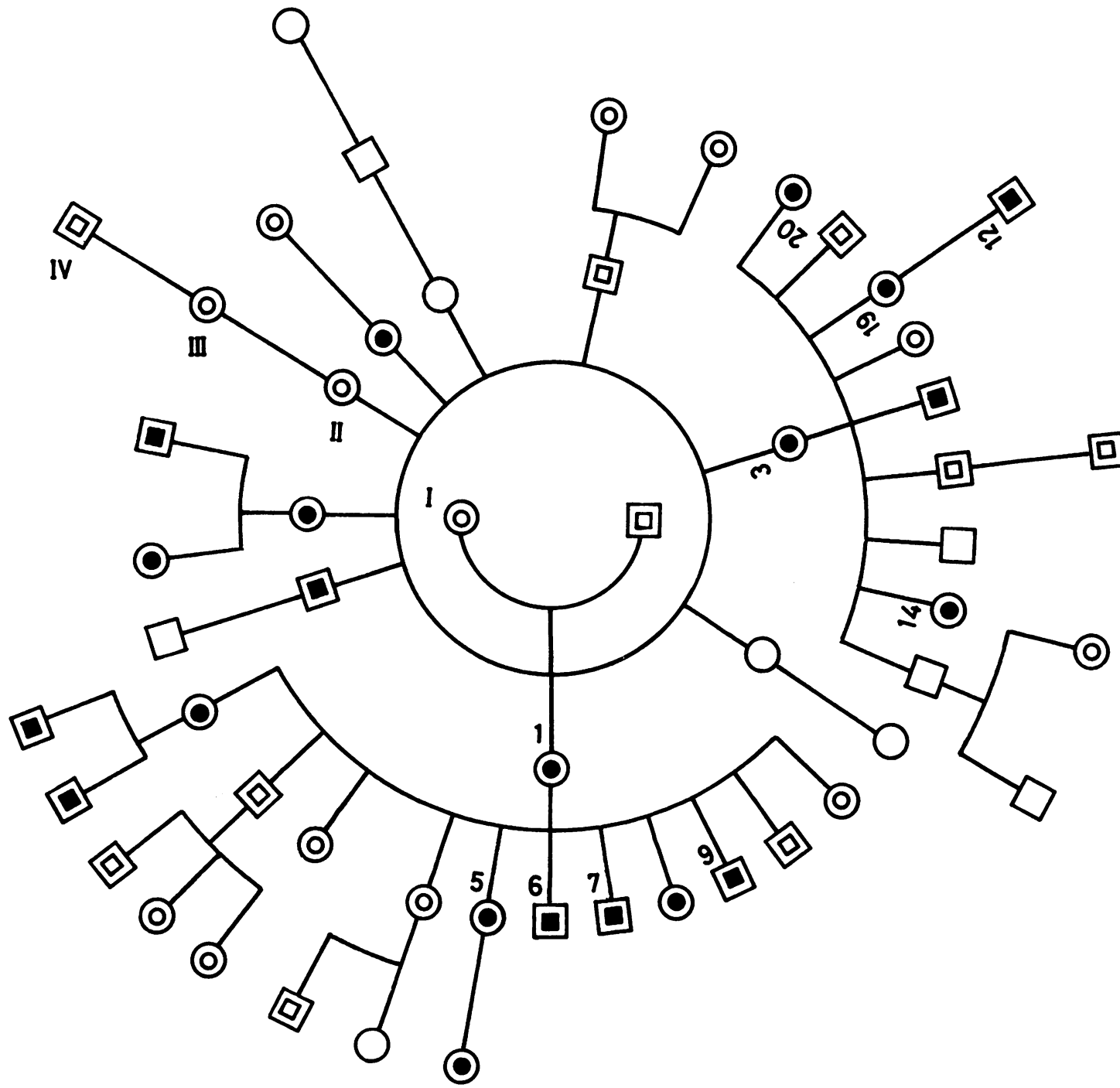

Fig 1 The pedigree of the Dutch family: $\square$ male; $\bigcirc$ female; 10 male investigated; ๑ female investigated; $\square$ male affected; O female affected; $\mathrm{O}$ index case.

cal examination revealed no abnormality of the cranial nerves, upper extremities or trunk. Intelligence was normal. A severe flaccid paresis of the upper part of the legs and paralysis of the distal part with distinct atrophy of the muscles and absence of the myotatic reflexes was found. Bladder control and sensation were normal. Laboratory investigations of blood, urine and cerebrospinal fluid were normal. Radiographs of the skull and the spine showed only spina bifida of the first sacral vertebra. Secondary abnormalities of the pelvis and the upper part of the legs consisted of coxa valga and subluxation of the hips. Radiographs of the knees and feet showed secondary demineralisation and deformity of metatarsal bones of both feet.
Case 2: From birth the mother of the index case (fig 1: II; 3 and fig 2) had slight contractures of joints of the lower extremities and scoliosis. This resulted in difficulties in locomotion. As far as she could remember, she has had these all her life. At the thoracic level she had a kyphosis and scoliosis and at the lumbar level an exaggerated lordosis due to flexion contractures of the hips. Flexion of the knees was restricted to $60^{\circ}$. She had slight talipes varus on the right. Neurological examination revealed flaccid paresis of the dorsiflexors of the ankles and paresis of the right peroneus muscle. The ankle reflexes were diminished on both sides. No other neurological abnormalities were found and radiographs of the spine were normal. 


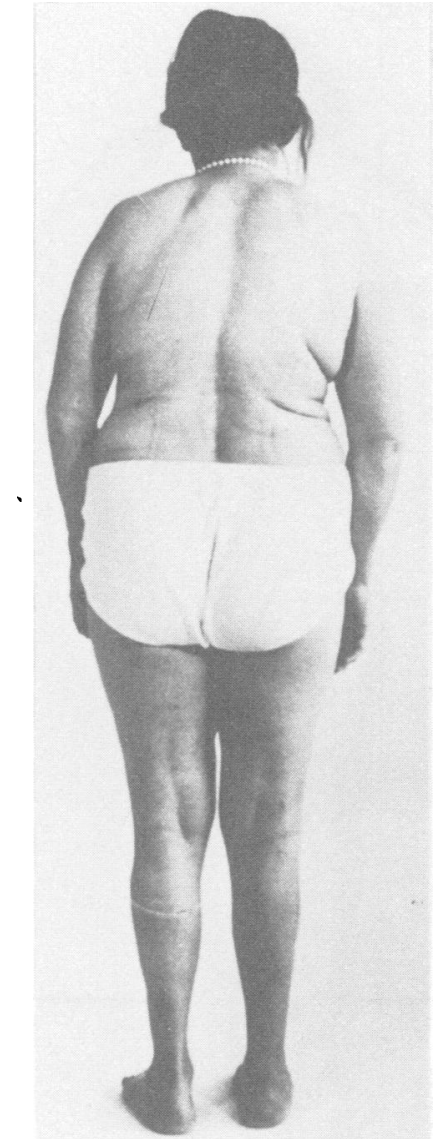

Fig 2 Case 2, member of the family II;3.

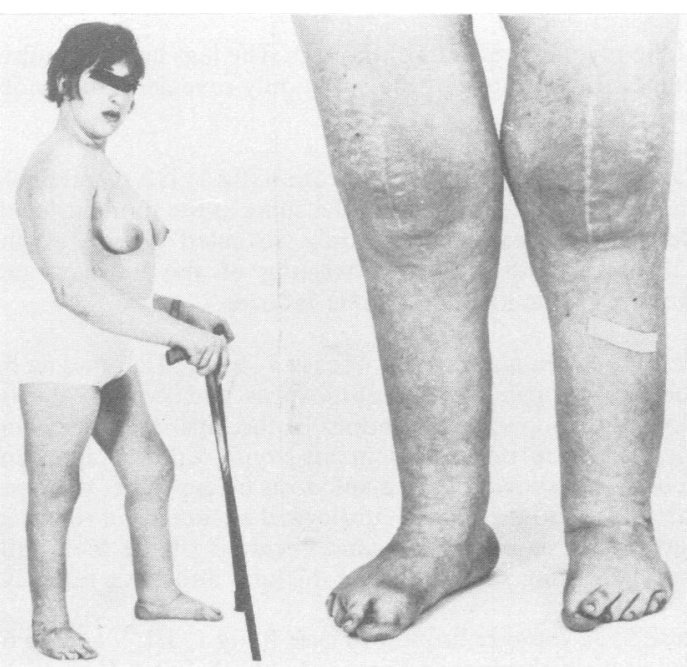

Fig 3 Case 6, member of the family III;5.

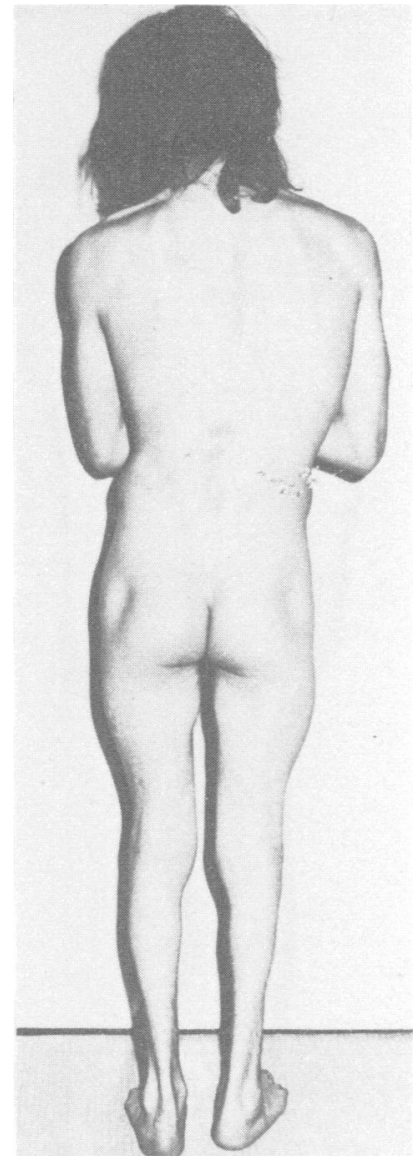

Fig 4 Case 7, member of the family III;6.

Case 3: The eldest sister of the index case (fig 1: III; 14 and fig 7) had a history of disability of locomotion in childhood due to paresis with atrophy of the right leg. She had scoliosis convex to the left and exaggerated lordosis at the lumbosacral level. Flexion in the right knee and extension in the right ankle was slightly restricted. Neurological examination only revealed flaccid paresis of the right leg with muscle wasting and absent patellar reflex. Radiographs of the spine showed evidence of spina bifida at the level of the first sacral vertebra.

Case 4: An elder sister of the index case (fig 1: III; 19 and fig 8 ) had only slight difficulty in walking. She had exaggerated lumbar lordosis and bilateral pes planus. Neurological examination only revealed paresis of dorsiflexors of both ankles, with wasting of the muscles of the distal part of both legs and absence of knee and ankle reflexes.

Case 5: A boy, the only child of case 4 was born after an uneventful pregnancy and labour. (Fig 1: IV; 12 and fig 10). At birth he showed contractures of the hips in flexion 


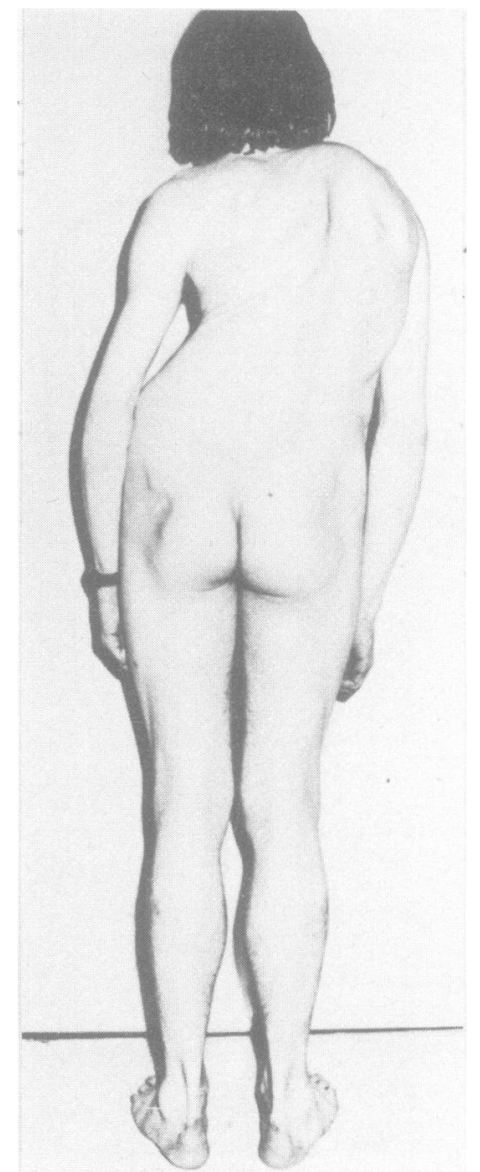

Fig 5 Case 8, member of the family III;7.

and abduction, flexion contractures of the knees and talipes equinovarus at both sides. He showed thoracic scoliosis with convexity to the right. Neurological examination revealed a severe flaccid paresis of the upper part of the legs and paralysis of the distal part with distinct atrophy of the muscles and absence of the myotatic reflexes. No other neurological abnormalities were found.

Case 6: The daughter of the eldest sister of case 2 (fig 1: III; 5 and fig 3) was born after a very difficult delivery, owing to congenital flexion contractures of the legs. Eventually she was able to walk after several orthopaedic corrections. The patient was very short and at the thoracic level the spine showed scoliosis convex to the left and kyphosis and at the lumbar level scoliosis convex to the right with torsion, and exaggerated lordosis due to forward tilt of the pelvis. The latter was the result of the flexion contractures in the hips. Flexion in the knees was limited to $100^{\circ}$ and there was bilateral talipes planus. She could only walk with crutches. Neurological examination revealed severe symmetrical proximal paresis of the legs and symmetrical paralysis of the distal part of the legs, with absence

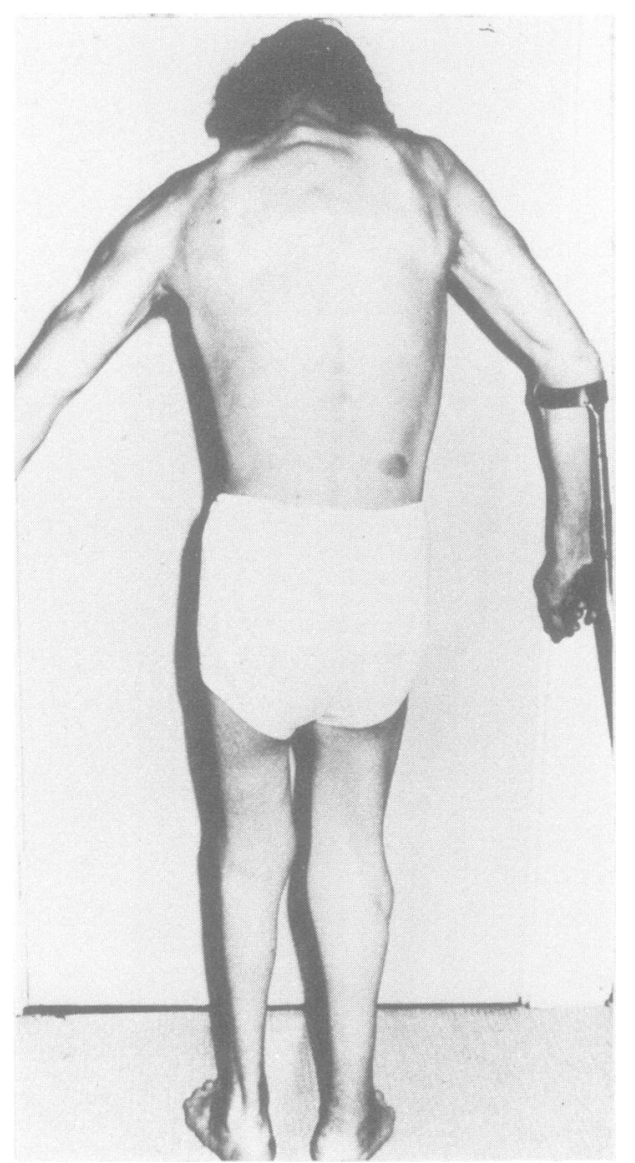

Fig 6 Case 9, member of the family III;9.

of the myotatic reflexes of the legs. The legs had a cylindric shape. Radiographs of the spine only revealed the abnormal curvatures.

Case 7: A younger brother of case 6 (fig 1: III; 6 and fig 4) had severe kyphoscoliosis of the spine at the thoracic level. Neurological examination only revealed a very slight paresis of both legs with wasting of the muscles and absence of the knee and ankle reflexes.

Case 8: A younger brother of case 7 (fig 1: III; 7 and fig 5) showed at birth talipes equinovarus and kyphoscoliosis. Several orthopaedic operations of the hips, the knees and the feet were performed in his youth without apparent benefit. He showed severe ankylosis of the spine, the hips, the knees and the feet. Neurological examination revealed flaccid paresis of the legs and paralysis of the feet, with muscle wasting and absence of the knee and ankle reflexes.

Case 9: A younger brother of case 8 (fig 1: III; 9 and fig 6) had at birth clubfeet and severe kyphoscoliosis. He underwent many orthopaedic operations. His abnormalities were 


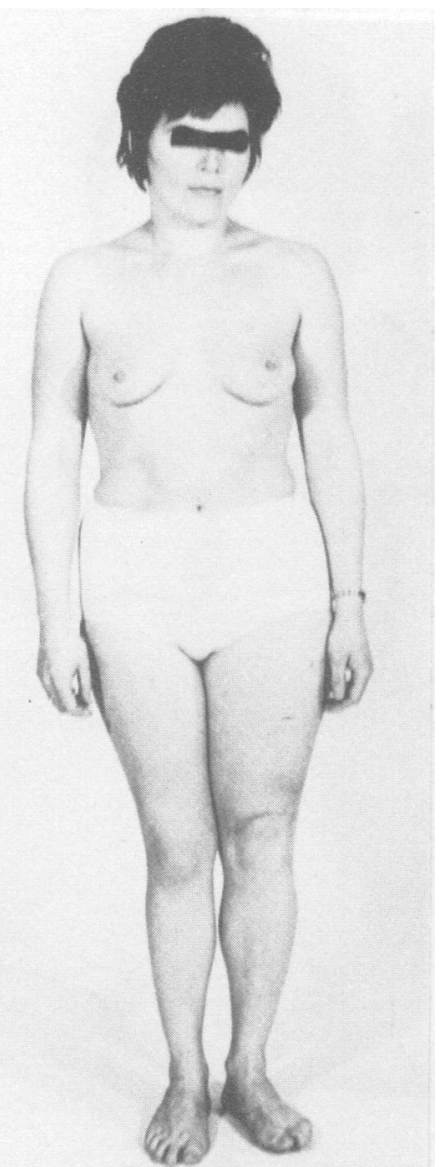

Fig 7 Case 3, member of the family 111;14.

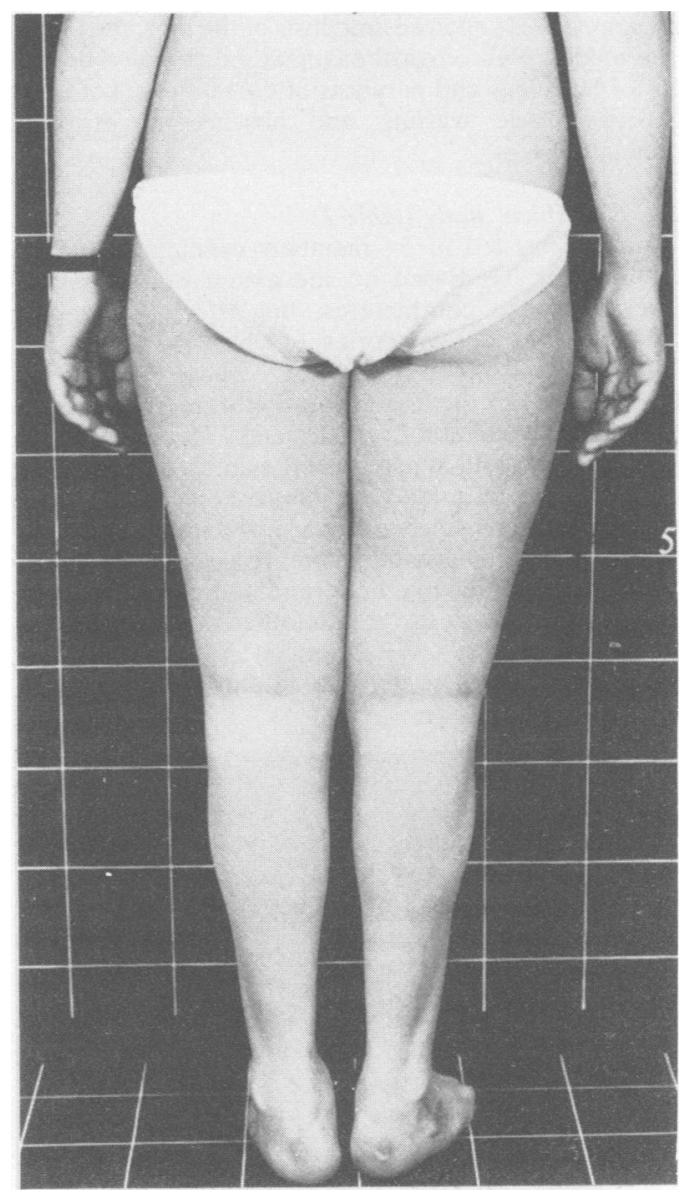

Fig 8 Case 4, member of the family III;19.

Table 1 Clinical features

\begin{tabular}{|c|c|c|c|c|c|c|c|}
\hline $\begin{array}{l}\text { Case } \\
\text { Number }\end{array}$ & $\begin{array}{l}\text { Member of } \\
\text { the family }\end{array}$ & Sex & Age (yr) & Category & $E M G$ & Histology & Figure \\
\hline - & II;1 & $\mathbf{F}$ & 66 & $\mathbf{I}$ & - & - & - \\
\hline 2 & II;3 & $\mathbf{F}$ & 63 & III & + & + & 2 \\
\hline - & II;6 & $\mathbf{F}$ & 57 & IV & - & - & - \\
\hline - & II; 8 & $\mathbf{F}$ & 54 & III & - & - & - \\
\hline - & II;9 & $\mathbf{M}$ & 50 & III & - & - & - \\
\hline $\bar{c}$ & III;1 & $\mathbf{F}$ & 42 & I & - & - & - \\
\hline 6 & III;5 & $\mathbf{F}$ & 38 & IV & + & - & 3 \\
\hline 7 & III;6 & $\mathbf{M}$ & 37 & IV & - & - & 4 \\
\hline 8 & III; 7 & $\mathbf{M}$ & 35 & IV & - & - & 5 \\
\hline- & III; 8 & $\mathbf{F}$ & 33 & III & - & - & - \\
\hline 9 & III;9 & $\mathbf{M}$ & 32 & IV & - & - & 6 \\
\hline 3 & III; 14 & $\mathbf{F}$ & 40 & III & + & + & 7 \\
\hline- & III;17 & $\mathbf{M}$ & 34 & I & - & - & - \\
\hline 4 & III;19 & $\mathbf{F}$ & 28 & I & + & + & 8 \\
\hline 1 & III;20 & $\mathbf{F}$ & 20 & IV & + & - & 9 \\
\hline - & III;27 & $\mathbf{M}$ & 21 & II & - & - & - \\
\hline - & III; 28 & $\mathbf{F}$ & 19 & III & - & - & - \\
\hline - & IV;1 & $\mathbf{M}$ & 20 & III & - & - & - \\
\hline - & IV;2 & $\mathbf{M}$ & 18 & III & - & - & - \\
\hline$\overline{5}$ & IV;8 & $\mathbf{F}$ & 17 & I & $\bar{t}$ & $\bar{t}$ & $\overline{10}$ \\
\hline
\end{tabular}


not progressive. He showed ankylosis of the hips, the knees and the ankles. Neurological examination revealed flaccid paresis of both legs and paralysis of dorsal flexors of both feet with muscle wasting and absence of myotatic reflexes in the legs.

Data of the clinical study (table 1)

The family consisted of 54 members running through 4 generations (fig 1). Based on the extent of the muscle weakness and the contractures, the affected members were divided into four categories, of which the criteria are given in table 2 .

Both members of the first generation were investigated. It was doubtful whether the female aged 77 was affected or not. She had a very slight paresis of the dorsal flexion of the feet and absence of ankle reflexes. Although these signs are of dubious significance at her age, she might belong to the first category. Her granddaughter (case 4, fig 1: III; 19) told us that she walked like her grandmother and her aunt (fig 1: II; 1). Moreover the grandmother's mother had the nickname "the cripple". We examined in the second generation seven of the nine persons, in the third generation

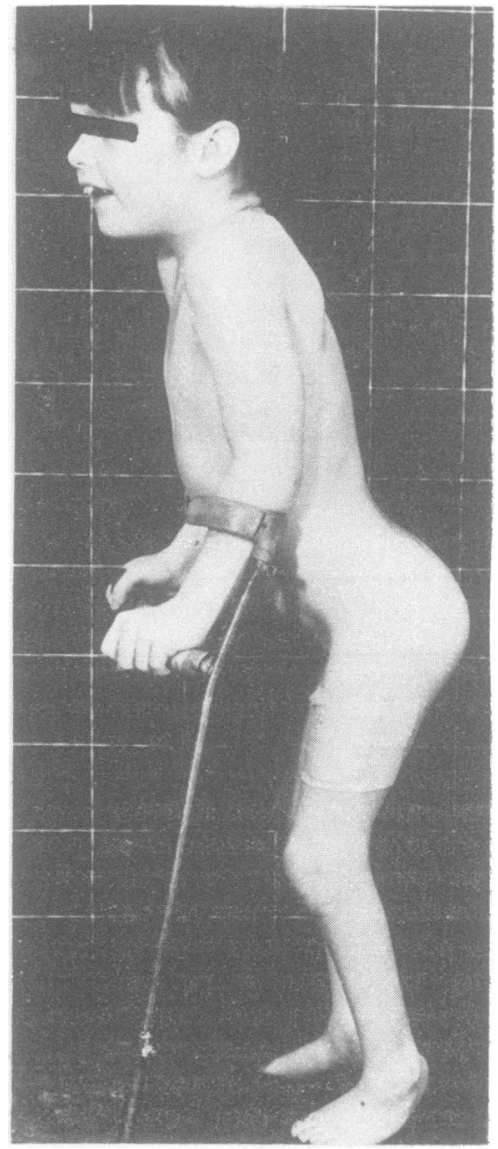

Fig 9 Case 1, (index case), member of the family 111;20.

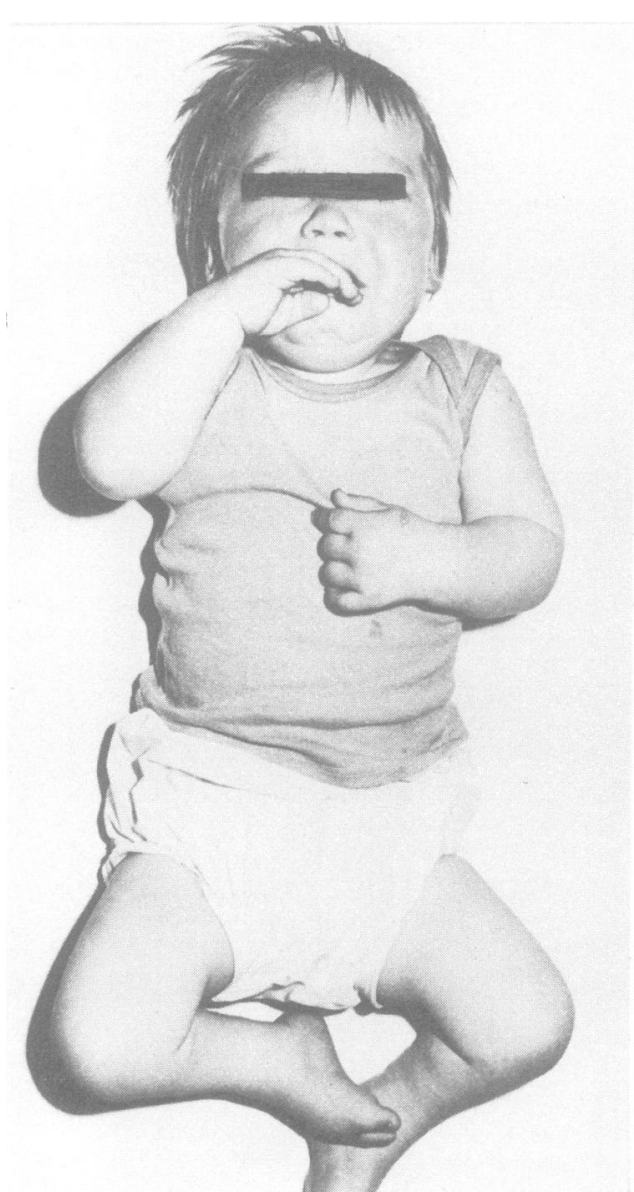

Fig 10 Case 5, member of the family IV;12.

24 of the 29 persons and in the fourth generation 11 of the 14 persons. Data of the remaining 10 members of the family were incomplete. However, as far as could be traced, they had no complaints.

We found in the second generation five affected cases, in the third generation 12 affected cases and in the fourth

Table 2 Categories based on the extent of the neuromuscular disease and the deformities

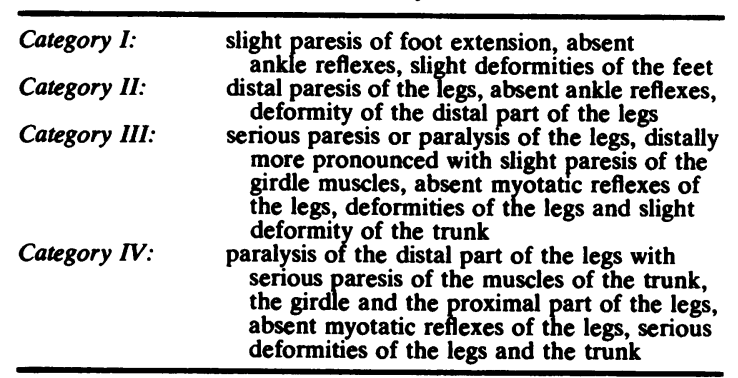


generation four affected cases. All the cases were children of affected members of the family. Difference in the number or seriousness of the disease in the two sexes was not significant. Twelve cases were female and nine cases were male. Of the female cases four were in the first category, five in the third category and three in the fourth category. Of the male cases one was in the first category, one in the second, four in the third and three in the fourth category.

Only one of the male cases was married. He was the only male case with a child, a normal boy.

The condition was present at birth and was not progressive clinically. In only three cases were we informed about the fetal movements during pregnancy (cases III; 20, IV; 2 and IV; 12). Two mothers did not notice any abnormality, but it was their first pregnancy. The mother of the index case experienced decreased fetal movements during the whole pregnancy.

The prominent features were the contractures and the muscle weakness. The contractures were of the mixed type that is limitation of flexion and extension, with the flexion deformity as the more disabling. The muscles at the most severely affected joints were found to be weakest. In nine patients the disorder was restricted to the lower extremities. In 12 patients the muscles of the trunk were also involved, leading to deformities of the lower spine and in five cases of the thorax as well. In none of the patients were the upper extremities involved. In most patients the muscle weakness increased from cranial to caudal levels, or from proximal to distal. The paretic or paralysed muscles were flaccid and atrophic with a single exception. The myotatic reflexes of the legs were diminished or absent. No other neurological signs were found. None of the patients showed fasciculations.

\section{Electrodiagnostic studies}

Electromyography with concentric needle electrodes was performed in six patients in deltoideus, biceps brachii, quadriceps femoris, biceps femoris, gluteus maximus, gluteus medius, erector spinae, adductor magnus, gastrocnemius, tibialis anterior, tibialis posterior, peroneus or extensor digitorum brevis muscles. Motor nerve conduc- tion velocity (MNCV) of the superficial peroneal nerve was determined in five of these cases. In the index case the somatosensibly evoked potentials at the feet were determined. The results of electromyography and the determination of MNCV is shown in table 3. In all the muscles the insertion potentials were normal. In none of the muscles was spontaneous denervation activity at rest found. The duration of the potentials was increased. The results of electromyography are in concordance with the neurogenic lesions. MNCV of the superficial peroneal nerve was within normal limits. The somatosensory evoked potentials in the feet of the index case show normal latency, forms and amplitudes. Calculated sensory nerve conduction velocity of the peroneal nerve was $50 \mathrm{~m} / \mathrm{s}$, also a normal value.

\section{Histological and histochemical findings}

The results of biopsies from the quadriceps femoris muscle of four patients (the biopsy specimens of the index case and of case 6 contained only fatty tissue without muscle fibres) were:

Case 2: Large groups of muscle fibres with normal diameter were present next to large groups of small angulated muscle fibres containing hyperchromatic and pyknotic nuclei. The small fibres had a high activity of oxidative enzymes. In addition in these fibres many characteristic targets in the transverse sections (fig 11A) and the longitudinal sections were seen. There was no type grouping. Case 3: Slight variation of muscle fibre diameter without groups of atrophic muscle fibres. Many characteristic target fibres were present. Histochemically there was a predominance of the type II muscle fibre (fig 11B). Fibre type was not differentiated by the oxidative enzymes.

Case 4: Slight variation of muscle fibre diameter. Some very small round fibres were present. In addition characteristic target fibres were seen (fig 11C) in the transverse and longitudinal sections. Histochemically there was a predominance of the type II muscle fibres.

Case 5: Almost complete replacement of the muscle tissue by fatty tissue. Only some groups of very small round fibres were observed next to groups of muscle fibres with normal diameter. The small fibres were of type I with a high activ-

Table 3 Results of electromyography and the determination of $M N C V$

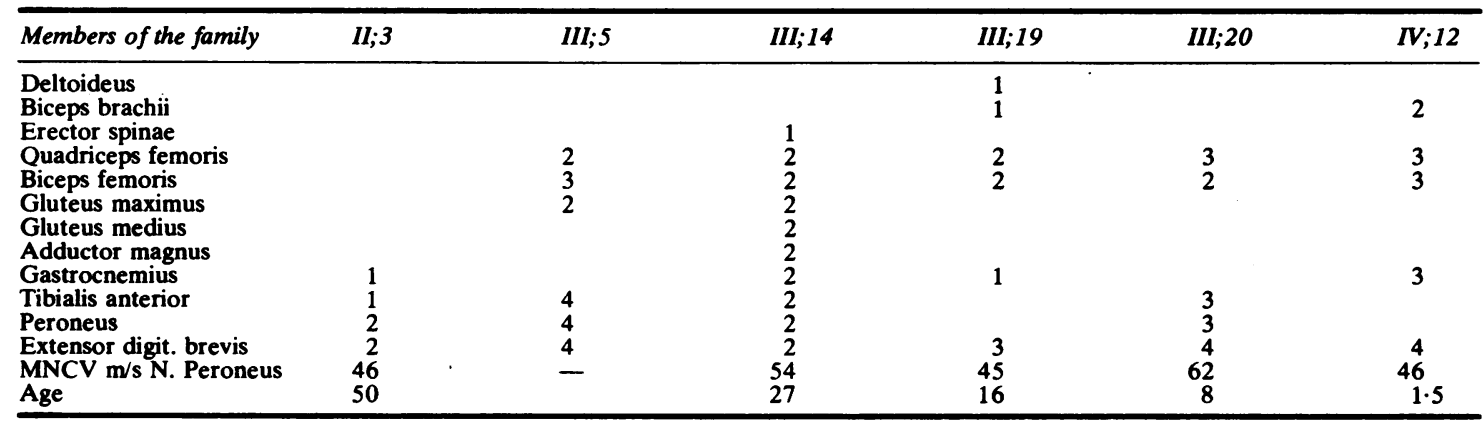

$1=$ Interference or mixed pattern; $2=$ Mixed or single pattern with complex, high voltage $(>1.000 \mathrm{mV})$ action potentials and reduction of action potentials; $3=$ single pattern with low voltage $(<500 \mathrm{mV})$ action potentials and strong reduction of action potentials; $4=$ no action potentials.

pormal value for MNCV in peroneal nerve according to Ludin (17): $55.941-0.155 \times$ age, SD = 4.055 m/s. 


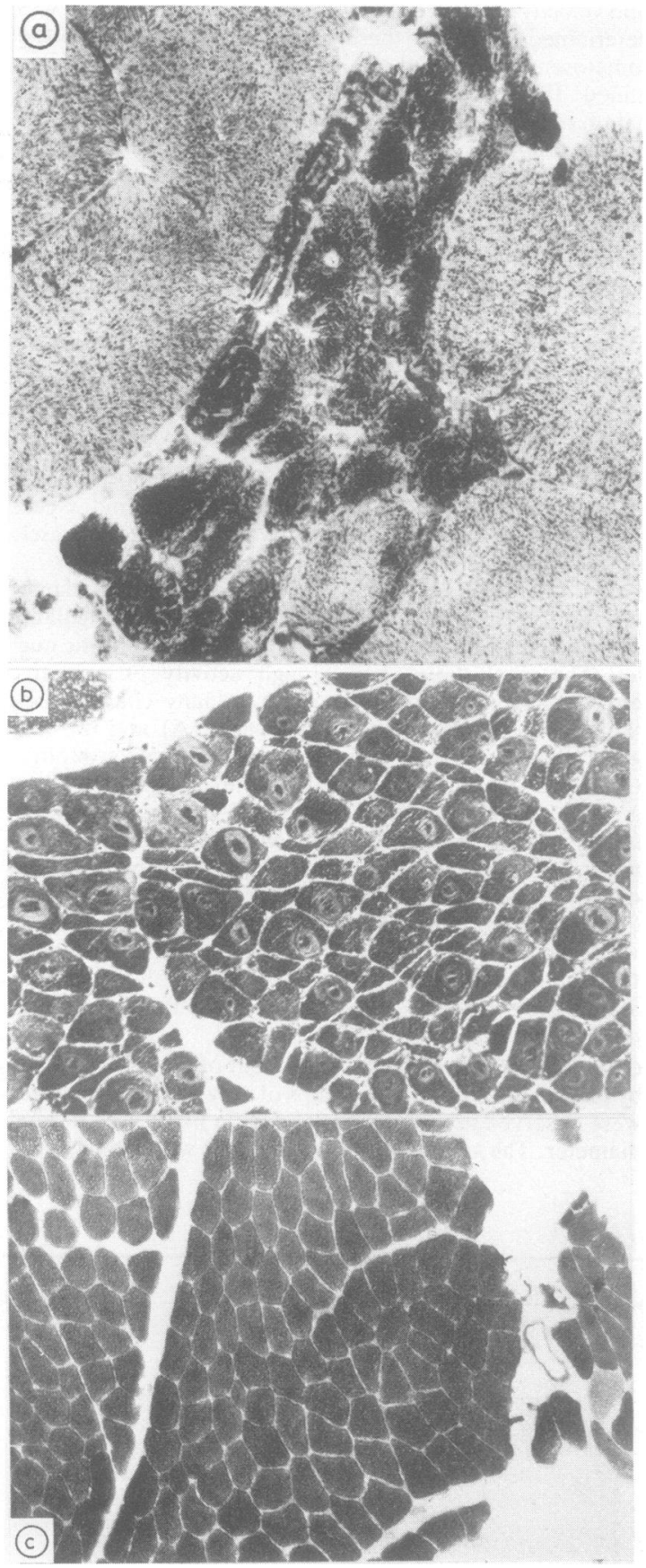

Fig 11 Muscles biopsies: A: Case 2:

DPNH ${ }^{+}$-tetrazonium reductase: Groups of type II muscle fibres with normal diameter, next to groups of small angulated type I muscle fibres with characteristic targets. ( $\times 552)$ B: Case 3: Gomori: Characteristic target fibres in the transverse section. $(\times 150) C$ : Case 4: ATPase: Type II predominance. $(\times 138)$ ity of the oxidative enzymes.

Thus there were 2 biopsies with typical neurogenic features, while the two other biopsies showed a picture that could be in concordance with long standing denervation.

\section{Muscular CT scan of the index case}

Eight computed tomographic slices were made at the level of the 6th cervical vertebra, the 4th and 9th thoracic vertebra, the 4th lumbar verterbra, the upper edge of the acetabulum, the lower edge of the obturator foramen, half way down the thigh and the proximal third of the leg. The first slice showed no abnormal muscles. On the second and third slice a secondary hypertrophy without changes in density of the deltoid, subscapularis, rhomboid, pectoral major, latissimus dorsi and triceps brachii muscles was seen. The 4th slice at the level of the 4th lumbar verterbra showed hypodensity of the paraspinal muscles. No abnormalities were seen in the anterolateral abdominal wall muscles, at that level (fig 12A). The two slices in the pelvic region showed complete hypodensity of the gluteal musculature (except the medial part of the gluteus maximus muscle on both sides) and of the rectus abdominis, quadriceps and rectus femoris, obturatorius externus, tensor fasciae latae, adductor brevis and vastus lateralis muscles. The pectineus and sartorius muscles were not involved (fig 12B and $C$ ). The slices through the thigh were almost completely hypodense, except for some parts of the rectus and biceps femoris muscles (fig 12D). The slices through the leg were almost hypodense except for some parts of the soleus muscle and the medial and lateral head of the gastrocnemial muscle. The muscles of the left leg were less hypodense than the muscles of the right leg (fig 12E).

\section{Discussion}

The signs described in eight of the nine case histories are consistent with a neurogenic disorder, associated with arthrogryposis multiplex congenita. In only 15 affected members was the muscle weakness so severe, that it led to arthrogryposis. In case 4 and in seven other cases belonging to categories I and II, muscle weakness was mild and congenital contractures were not present. The expression of the disorder in the members of this family varies widely. Therefore the diagnosis might be missed in some cases of category I.

The nature of the neuromuscular disorder seems to be neurogenic. The paresis or paralysis with muscle wasting accompanied by reduced or absent myotatic reflexes makes this likely. Electromyography supported this diagnosis in six cases, histological and histochemical studies in four of these six cases.

The normal MNCVs make a hereditary motor and sensory neuropathy very unlikely. In 173 cases of type I hereditary motor and sensory neuropathy described by Harding and Thomas, ${ }^{6}$ the mean value for MNCV in the peroneal nerve was $16.6 \pm 7.7 \mathrm{~m} / \mathrm{s}$. In type II hereditary motor and sensory neuropathy 
A dominantly inherited lower motor neuron disorder presenting at birth with associated arthrogryposis 1045
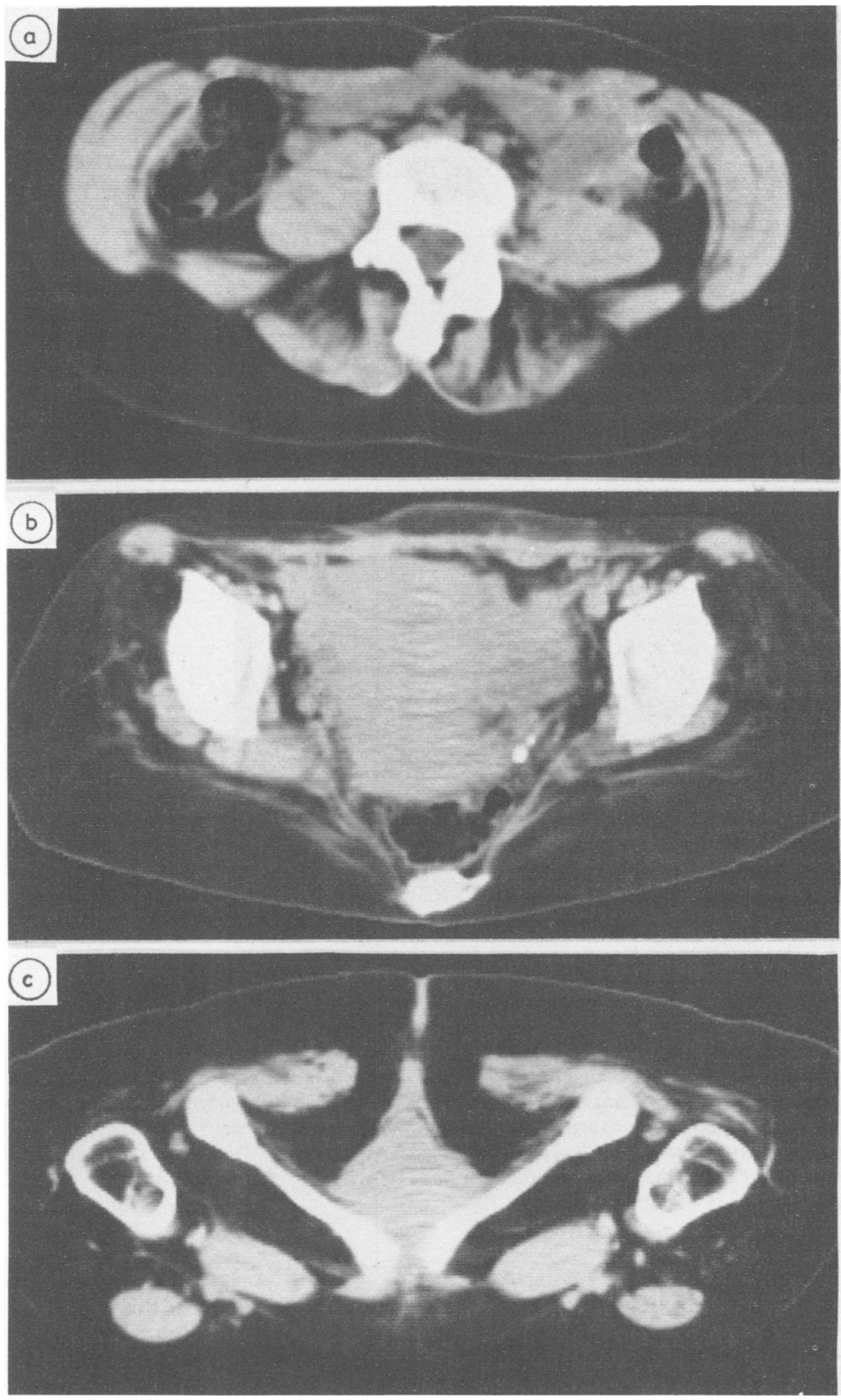

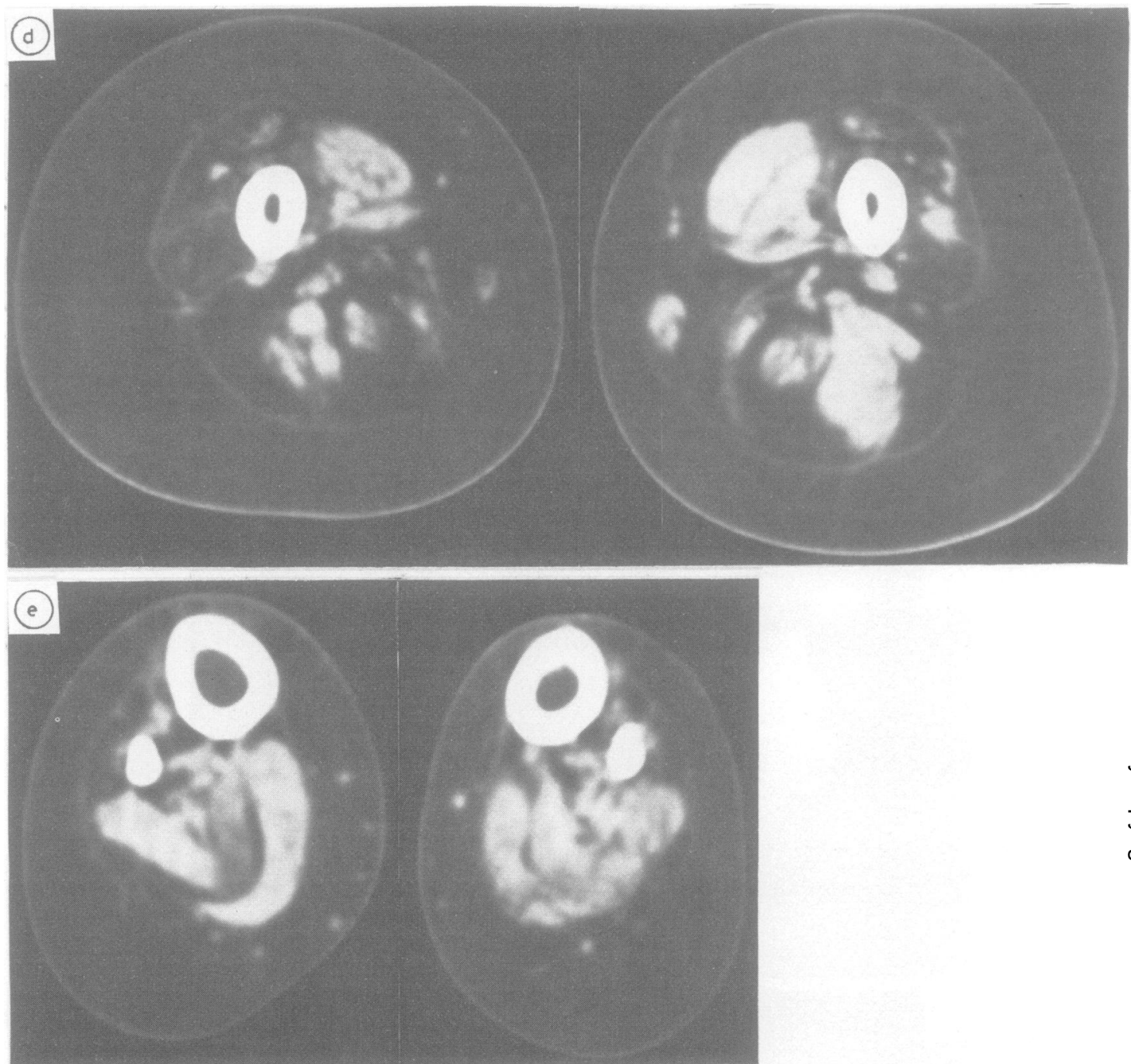

Fig 12 Muscular CT scan of the index case: (A) Slice at the level of the 4th lumbar vertebra: hypodensity of the paraspinal muscles. (B) Slice at the level of the upper edge of the acetabulum: almost complete hypodensity of the gluteal musculature and complete hypodensity of the rectus abdominis. (C) Slice at the level of the bottom of the obturator foramen: complete hypodensity except for the pectineus and sartorius muscles. (D) Slice through the thigh: almost complete hypodensity except for some parts of the rectus and biceps femoris. (E) Slice through the lower leg: almost complete hypodensity except for some parts of the soleus muscle and the medial and lateral head of the gastrocnemius muscles.

the degree of reduction of $\mathrm{MNCV}$ is less. Harding and Thomas $^{6}$ described a mean value for MNCV in the peroneal nerve of $44.2 \pm 10.1 \mathrm{~m} / \mathrm{s}$ in a group of 55 cases with type II hereditary motor and sensory neuropathy. Weakness of the upper limbs occurred in only $50 \%$ of the patients with type II hereditary motor and sensory neuropathy, while $60 \%$ had no clinically demonstrable sensory impairment. ${ }^{6}$
The normal sensory nerve conduction velocity in the peroneal nerve of the index case does not fit the diagnosis hereditary motor and sensory neuropathy. Nevertheless the diagnosis type II hereditary motor and sensory neuropathy cannot be excluded completely without nerve biopsy. This procedure was refused by our patients. However, a spinal origin of the lesion in our cases is suggested although 
this cannot be proved without necropsy.

Congenital contractures in spinal muscular atrophy type I are usually mild or absent; also the course is progressive and not stationary as in our cases. In anterior horn cell degeneration the ankylosis may be severe with a minimal range of movement capacity of most joints and all four limbs are often involved, but a bimelic involvement often occurs. Darwish et al described three cases with non-progressive muscle weakness and congenital contractures restricted to the upper extremities due to a symmetrical lower motor neuron deficit, for which the term congenital cervical spinal atrophy was used.

In our cases muscle weakness, congenital contractures, electromyographical abnormalities (investigated in three cases in the upper extremities) and hypodensity of the muscles on muscular CT scan (in the index case) were restricted to the trunk and the lower extremities. The upper extremities were not affected.

In cases of anterior horn cell degeneration some features such as dimpling of the skin, ${ }^{8}$ and dermatoglyphic abnormalities ${ }^{9}$ are seen. Often a history of decreased fetal movement during the pregnancy is given by the mother of the cases. These signs may be regarded as indications of a fetal insult occurring early in pregnancy. We did not notice dimpling of the skin in our patients. The dermatoglyphic patterns were not investigated in our cases. Cylindric shape and contraction deformities, especially of the distal parts of the legs, were found in several cases. Unfortunately the results of the histological and histochemical studies of four muscle biopsies are not sufficient to differentiate the causal defect. However histological studies of cases of anterior horn cell degeneration demonstrated similar abnormalities as in our cases, a marked increase in fatty and connective tissue, associated with denervation atrophy and fibre type predominance..$^{10}$ Probably the patterns of deformity were consistent with specific levels of segmental deficit. The relation with localised lesions of the anterior horn cell columns as proposed by Brown et $a^{11}$ and by Drachman et $a^{12}$ can only be proved by necropsy studies.

The high proportion of persons afflicted with this rare congenital disease in a single kindred leaves little doubt that the condition is most likely due to heterozygosity of a dominant gene. X-linked dominance is improbable but could not be excluded because the only affected father has no daughters. However, the expression is the same in the male and female cases. The length of the X-chromosome is about $1 / 20$ of the total length of the haplotype, so that the chance that the responsible gene is situated on an autosome is 19 times greater than location of the $\mathrm{X}$-chromosome. Both facts make autosomal dominant inheritance very probable.

The overall segregation ratio within the affected family is close to a fully penetrant dominant gene. We examined 26 of 28 children of eight affected members of the family. Of these 26 members, 16 were affected. With these numbers the lowest probability of showing signs is 0.47 with a reliability of $95 \%$. In case of a $100 \%$ penetrant dominant gene the probability is 0.50 with a reliability of $95 \%$. The expression of the gene is very varied.

Spinal muscular atrophy with autosomal inheritance, with congenital onset, leading to arthrogryposis has been described by Lugaresi et al. ${ }^{3}$ The condition was limited to the lower limbs. In this condition there appeared to be an arrest of the disease process in late infancy. The congenital contractures were mild. A man and his son are described. Probably two brothers of the index case had the same disorder, which may have remarkable similarities with the presently described disorder. In anterior horn cell degeneration a sporadic nongenetic nature is assumed, ${ }^{1314}$ although once an autosomal recessive inheritance was suggested. ${ }^{15}$ In "the Pena-Shokeir I Syndrome" the lesion is not restricted to reduction of the anterior horn cells. Multiple developmental abnormalities in the cerebrum and cerebellum have been noted in this syndrome; also the mode of inheritance is autosomal recessive. ${ }^{16}$ Autosomal dominant inheritance of a non-progressive lower motor neuron disorder present at birth with associated arthrogryposis has not been described, but might be missed when the clinical manifestations are very dissimilar, or when there are fewer offspring than in the family we described.

This paper also demonstrates that in cases of arthrogryposis a careful diagnosis of the underlying cause must be made for genetic counselling.

We thank J Bethlem, MD, Professor of Neurology and FGI Jennekens, MD, neurologist for the examination of the muscle biopsies, WHJM Hootsmans and FE Posthumus Meyes MD, neurologists for the electrodiagnosis studies, F Piessens, neurologist for collecting many data of the family, BWJM Verbeeten for his comments on the muscular CT scan, Miss M Verjaal, MD for her interpretation of the genetic data and Mrs M Goosmann-Michielsen and Miss SY Majoor for typing the manuscript.

\section{References}

' Hageman G, Jennekens FGI, Vette JK, Willemse J. The heterogeneity of distal arthrogryposis. Brain Dev 1984;6:273-84.

${ }^{2}$ Vassilopoulos D, Emery AEH. Quantitative histochemistry of the spinal motor neurone nucleus during human fetal development. J Neurol Sci 
1977;32:275-81.

${ }^{3}$ Lugaresi E, Gambetti P, Giovannardi Rossi P. Chronic neurogenic muscle atrophies of infancy, their nosological relationship with Werdnig-Hoffman's disease. $J$ Neurol Sci 1966;3:399-409.

${ }^{4}$ Bargeton E, Nezelof C, Guran P, Job J-C. Etude anatomique d'un cas d'arthrogrypose multiple congenitale et familiale. Rev Neurol (Paris) 1961; 104:479-89.

5 Joosten EMG, De syndromen van Charcot-Marie-Tooth en van Dejerine-Scottas. Thesis 1982.

${ }^{6}$ Harding AE, Thomas PK. Hereditary distal spinal muscular atrophy. J Neurol Sci 1980;45:337-48.

' Darwish H, Sarnat H, Archer C, Brownell K, Kotagal S. Congenital cervical spinal atrophy. Muscle Nerve 1981;4:106-10.

${ }^{8}$ Hertel E, Stotz S, Jacobi HM, Murken JD. Zur diagnose der Arthrogryposis multiplex congenita. Arch Orthop Trauma Surg 1969;67:114-34.

' Eckel U, Spranger J, Klein H. Arthrogryposis multiplex congenita mit neurogener Muskelatrophie und Brachydaktylie. Klin Pädiatr 1979;191:325-9.

${ }^{10}$ Hageman G, Jennekens FGI, Klep-de Pater JM, Bijlsma JB, Willemse J. Comparative clinical and histological study of spinal muscular atrophy type I and anterior horn cell degeneration, leading to arthrogryposis. Neuroped 1983;14:121 (abstract).

"Brown LM, Robson MJ, Sharrad WJW. The pathophysiology of arthrogryposis multiplex congenita neurologica. J Bone and $J$ Surg 1980;62B:291-96.

${ }^{2}$ Drachman DB, Banker CA. Arthrogryposis multiplex congenita. Arch Neurol 1961;5:77-93.

${ }^{13}$ Hageman G, Willemse J. Arthrogryposis multiplex congenita. Review with comment. Neuropediatrics 1983;14:6-11.

${ }^{14}$ Hall JG. Nicht-chromosomal bedingte DysmorphicSyndrome. Klin Gen Paediatr. Mainz Symposium, 1980; 1:105-21.

${ }^{15}$ Rosenmann A, Arad J. Arthrogryposis multiplex congenita: neurogenic type with autosomal recessive inheritance. J Med Gen 1974;11:91-4.

${ }^{16}$ Pena SDJ, Shokeir MHK. Syndrome of camptodactyly, multiple ankyloses, facial anomalies and pulmonary hypoplasia. A lethal condition. J Pediatr 1974;85:373-84.

${ }^{17}$ Ludin HP. Electromyography in Practice. New York: George Thieme Verlag, 1980:146. 